\title{
Development of Costs for Complementary Medicine after Provisional Inclusion into the Swiss Basic Health Insurance
}

\author{
Hans-Peter Studer ${ }^{a}$ André Busato ${ }^{b}$ \\ ${ }^{a}$ Speicherschwendi, \\ ${ }^{\mathrm{b}}$ Institute for Evaluative Research in Orthopedic Surgery, University of Bern, Switzerland
}

\author{
Keywords \\ Complementary medicine $\cdot$ Health care costs . \\ Health insurance . Anthroposophic medicine . \\ Homeopathy · Neural therapy . \\ Traditional Chinese medicine $\cdot$ Health services research
}

\section{Summary}

Background: In 1999, 5 complementary procedures were included into the Swiss basic health insurance on a provisional basis. In consequence, many people expected a substantial increase of costs of up to CHF 110 million or even higher. Methods: Data on consultation costs at the expense of basic health insurance for the period of 1997-2003 were analyzed for 206 certified complementary and alternative medicine (CAM) physicians with 1 or multiple certificates for complementary medicine. The data was provided by the Swiss health insurers' data pool (santésuisse). The 2 major Swiss health insurers provided additional cost data of expenditures reimbursed by private health insurance for complementary medicine. This allowed a longitudinal analysis of consultation costs at the expense of basic health insurance and the costs of private health insurance of certified CAM physicians. Furthermore, those costs were compared to the respective costs of 119 non-certified CAM physicians and 145 physicians in conventional practices. Results: The development of consultation costs of certified CAM physicians at the expense of basic health insurance showed a net annual increase of CHF 54,200 per physician between 1998 and 2002 and of CHF 35.9 million for all 663 certified CAM physicians. On the other hand, costs at the expense of private health insurance for complementary medicine decreased in the same period by CHF 34,300 per certified CAM physician and by CHF 22.8 million for all 663 certified CAM physicians. Conclusion: The inclusion of 5 complementary disciplines into the Swiss basic health insurance led to an increase of costs, which was, however, much lower than predicted.

\author{
Schlüsselwörter \\ Komplementärmedizin · Gesundheitskosten · \\ Krankenversicherung - Anthroposophische Medizin . \\ Homöopathie · Neuraltherapie . \\ Traditionelle chinesische Medizin · Versorgungsforschung
}

\section{Zusammenfassung}

Hintergrund: Im Jahr 1999 wurden 5 Methoden der ärztlichen Komplementärmedizin provisorisch in die obligatorische Krankenpflegeversicherung (Grundversicherung) der Schweiz aufgenommen. Als Folge erwarteten viele einen substanziellen Kostenanstieg von gegen 110 Millionen (Mio.) CHF oder sogar mehr. Methodik: Für 206 zertifizierte Komplementär- und Alternativmedizin (CAM)-Ärzte mit 1 oder mehreren komplementärmedizinischen Fähigkeitsausweisen wurden für den Zeitraum von 1997 bis 2003 Daten zu den Konsultationskosten zulasten der Grundversicherung analysiert. Sie wurden vom Datenpool des Dachverbands der schweizerischen Krankenversicherer (santésuisse) zur Verfügung gestellt. Zusätzlich lieferten die 2 größten Krankenversicherer der Schweiz die Kostendaten, die die beteiligten Ärzte zulasten privater komplementärmedizinischer Zusatzversicherungen verrechneten. Dies erlaubte für die zertifizierten CAM-Ärzte eine Längsschnittanalyse der Entwicklung der Konsultationskosten zulasten der Grundversicherung und zulasten der komplementärmedizinischen Zusatzversicherung. Darüber hinaus wurden die entsprechenden Kosten mit denjenigen von nicht zertifizierten CAM-Ärzten und von Ärzten mit konventionellen Praxen verglichen. Ergebnisse: Die Entwicklung der Konsultationskosten von zertifizierten CAM-Ärzten zulasten der Grundversicherung zeigte für den Zeitraum von 1998 bis 2002 einen jährlichen NettoAnstieg von $54200 \mathrm{CHF}$ pro Arzt und von 35,9 Mio. CHF für alle 663 zertifizierten CAM-Ärzte. Demgegenüber sanken die Kosten zulasten der komplementärmedizinischen Zusatzversicherung im selben Zeitraum um $34300 \mathrm{CHF}$ pro zertifiziertem CAM-Arzt und um 22,8 Mio. CHF für alle 663 zertifizierten CAM-Ärzte. Schlussfolgerung: Die provisorische Aufnahme von 5 komplementärmedizinischen Methoden in die obligatorische Krankenpflegeversicherung der Schweiz führte zu einem Kostenanstieg, der jedoch weit kleiner ausfiel als ursprünglich vorausgesagt.

\section{KARGER \\ Fax +497614520714 \\ Information@Karger.de}

www.karger.com (c) 2011 S. Karger GmbH, Freiburg

1661-4119/11/0181-0015\$38.00/0

Accessible online at:

www.karger.com/fok
Dr. oec. Hans-Peter Studer

Rickstrasse 31

9037 Speicherschwendi, Switzerland

Tel. +41 71 34438-37, Fax -40

hpstuder@swissonline.ch 


\section{Introduction}

Between 1999 and 2005, 5 methods of complementary medicine were included in the compulsory Swiss basic health insurance on a provisional basis for a period of 6 years. In July 2005 , they were removed from basic health insurance by the Swiss Federal Department of Home Affairs, based on the argument that the efficacy, effectiveness and cost-efficiency of these methods had not been sufficiently proven. This decision led to a major debate whether it had been actually based on scientific data or whether it was rather politically motivated [1-3]. After a referendum in which two-thirds of the Swiss population voted for the integration of complementary medicine into the health system, there is now again a public debate whether complementary medicine should again be included in basic health insurance.

The 5 complementary disciplines that were provisionally part of basic health insurance during a 6-year period are: homeopathy, anthroposophic medicine, neural therapy, herbal medicine, and traditional Chinese medicine (TCM). Acupuncture as part of TCM had already been definitely included in 1996. However, medical services for alternative medicine were only reimbursed at the expense of basic health insurance if these methods were practiced by conventionally trained and licensed physicians with appropriate supplementary training in complementary and alternative medicine (CAM), i.e. with a respective certificate of the Swiss Medical Association (FMH).

Until now, a certificate for herbal medicine has not been recognized by the FMH. Therefore, medical procedures of herbal medicine were not reimbursable as such by basic health insurance and are not subject of this study. The same is true for CAM drugs. They are reimbursed since 1996 if they are registered on the specialties list of the Swiss Federal Office of Public Health, irrespective of whether they are prescribed by physicians with or without a certificate for complementary medicine.

With the implementation of certificates for complementary medicine, the number of physicians with 1 or multiple certificates constantly increased between 1999 and 2003 (table 1). However, these physicians still account for only a comparatively small proportion of primary care providers in Switzerland.

In 2002, the 762 physicians with 1 or multiple certificates for complementary medicine generated an estimated total consultation cost of Swiss Francs (CHF) 179.8 million at the expense of basic health insurance. Since these physicians provide a combination of complementary and conventional medicine, consultation costs include reimbursements for both [5].

Prior to the inclusion of 5 complementary disciplines in basic health insurance, the Swiss Federal Office for Social Security had estimated that this would increase costs for basic health insurance by a maximum of CHF 110 million per year. In contrast, the author of a much debated study [6,7] argued that this estimate 'would by far be insufficient' [8].

To estimate the real increase of costs due to the inclusion of CAM into basic health insurance, the following facts need to be considered: The respective physicians practiced a combination of complementary and conventional medicine already before 1999. At that time (and partially also in 2002), some costs for CAM were brought to account under tariff positions for conventional medicine. Furthermore, acupuncture as part of TCM had already been included in basic health insurance in 1996. However, these costs could not be covered by basic health insurance until July 1999 because the respective tariff position was lacking.

To evaluate the effective increase of costs as a consequence of the inclusion of the 5 complementary procedures, the question to be answered is: To what amount had consultation costs of certified CAM physicians risen between 1998 and 2002, in addition to the general increase of costs in primary care? Furthermore, it is of interest to see how a possible increase can be explained. For this purpose, this study aims at providing scientifically sound data to reach a decision on whether or not complementary medicine applied by certified physicians should again be included in Swiss basic health insurance.

\section{Material and Methods}

\section{Sampling Procedures}

Cost data were sampled in the context of a cross-sectional questionnairebased survey aimed at primary care providers working in single or group practices in Switzerland. In addition to the list of certified CAM physicians of the FMH in the year 2000, membership lists of the 5 societies for complementary medicine were obtained. All members working as primary care providers were asked to participate in the project. In addition, a list of all primary care providers in Switzerland was obtained from the
Table 1. Amounts and proportions of self-employed physicians with 1 or multiple official certificates for complementary medicine, 1999-2003 [13]

\begin{tabular}{llllllll}
\hline Year & $\begin{array}{l}\text { Anthroposophic } \\
\text { medicine }\end{array}$ & Homeopathy & $\begin{array}{l}\text { Neural } \\
\text { therapy }\end{array}$ & TCM & Total & $\begin{array}{l}\text { Total without } \\
\text { multiple certificates }^{\text {a }}\end{array}$ & $\begin{array}{l}\text { Total primary care } \\
\text { providers }^{\text {b }}\end{array}$ \\
\hline 1999 & 3 & 170 & - & 321 & 494 & - & 5,987 \\
2000 & 38 & 233 & 34 & 438 & 743 & 663 & 6,189 \\
2001 & 47 & 243 & 62 & 476 & 828 & 746 & 6,348 \\
2002 & 51 & 254 & 69 & 468 & 842 & 762 & 6,496 \\
2003 & 60 & 269 & 83 & 483 & 895 & 829 & 6,675 \\
\hline
\end{tabular}




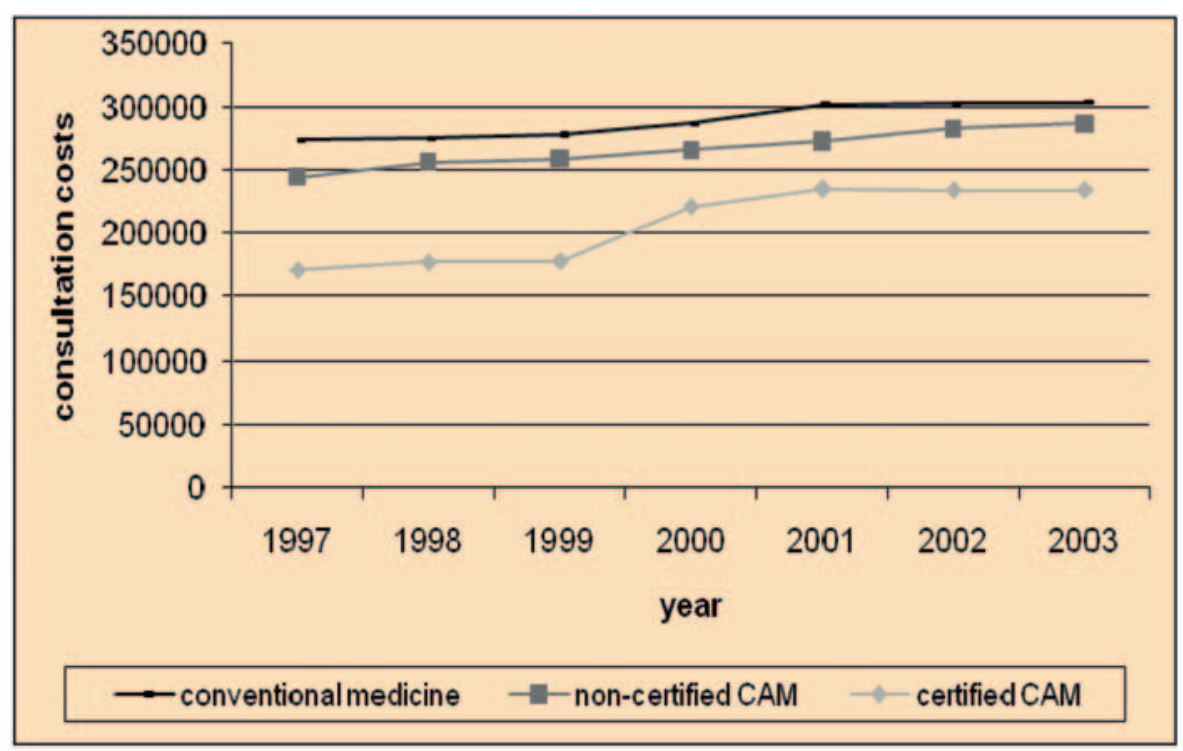

Fig. 1. Development of consultation costs at the expense of basic health insurance in 19972003 with respect to certified CAM physicians, non-certified CAM physicians, and COM physicians; average per physician in CHF. in order to detect multiple physicians using the same identification codes in the database of santésuisse (i.e. married couples). Data analysis was purely descriptive, with the main focus on the development of costs.

The development of total yearly consultation costs at the expense of basic health insurance as well as costs for complementary medicine at the expense of private health insurance were compared between COM, noncertified and certified CAM physicians. The shift of costs from private to basic health insurance for certified CAM physicians was then analyzed with respect to different complementary disciplines on the basis of the 663 certified CAM physicians in the year 2000. By comparing different groups of Swiss cantons to one another, we furthermore analyzed to what extent the observed increase of consultation costs could be explained by different causes. Cantons were grouped based on information received from regional branch offices of santésuisse and the Association of Swiss Medical Societies for Acupuncture and Chinese Medicine (ASA).

\section{Results}

\section{Increase of Average Consultation Costs of Certified CAM Physicians}

The comparison of average consultation costs at the expense of basic health insurance for the period from 1997 to 2003 shows lower costs for certified CAM physicians compared to non-certified CAM physicians and especially to COM physicians - however, without taking into account differences in patient populations [9]. Between 1999 and 2001 there was a considerable increase of consultation costs of certified CAM physicians, with the effect that, afterwards, the differences between groups of average consultation costs remained smaller (fig. 1).

In order to analyze the effect of the increase of consultation costs as a consequence of the provisional inclusion of 5 complementary disciplines in July 1999, we focused on the period from 1998 to 2002. After subtraction of the general increase of consultation costs of all primary care providers in Switzerland during that period $(4.4 \%)$, we estimated an increase of consultation costs of CHF 54,171 per certified CAM 
Fig. 2. Development of costs at the expense of private health insurance for complementary medicine from Helsana and CSS, in 1997-2003, with respect to certified CAM physicians, noncertified CAM physicians, and COM physicians; total in million CHF.
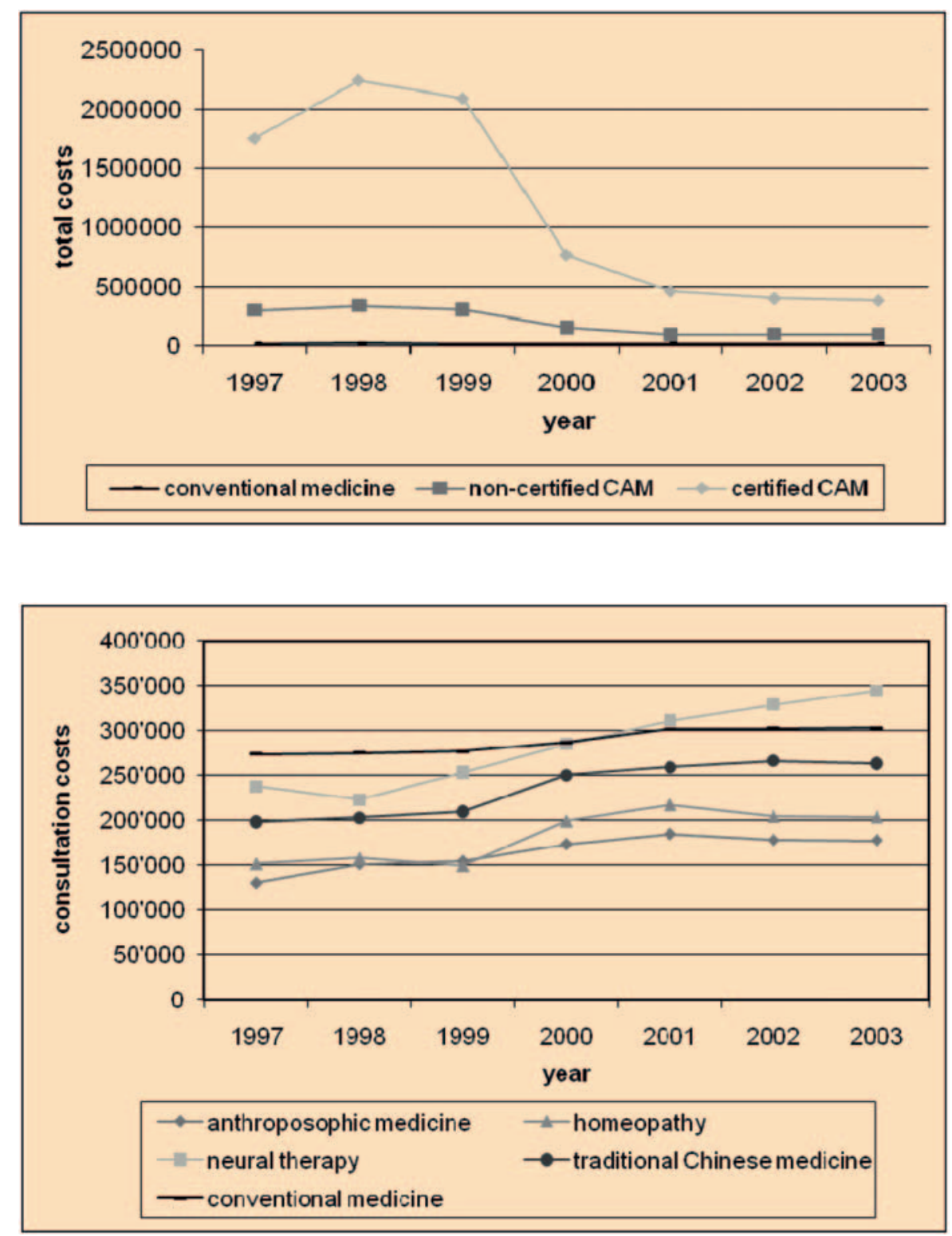

Fig. 3. Development of consultation costs at the expense of basic health insurance in 19972003 with respect to anthroposophic medicine, homeopathy, neural therapy, TCM, and conventional medicine; average per certified CAM physician in CHF. shift of CAM-related costs from private to basic health insurance.

Between 1998 and 2002, reimbursements for complementary medicine by private health insurances show a decrease mainly for certified CAM physicians (fig. 2). For non-certified CAM physicians, the respective costs and their decrease were much lower. For the 2 health insurers included in the study, the nominal decrease for all certified CAM physicians within our sample amounted to CHF 1.8 million.

We linked data of costs at the expense of private health insurance for complementary medicine per physician to costs at the expense of basic health insurance and extrapolated private health insurance costs to the total of all Swiss health insurers and to the total of all certified CAM physicians in the year 2000. Due to a lack of the respective data, we thereby calculated with the same general increase of costs at the expense of private health insurance for complementary medi- 
Fig. 4. Development of costs at the expense of private health insurance for complementary medicine from Helsana and CSS, in 1997-2003, with respect to anthroposophic medicine, homeopathy, neural therapy, and TCM; average per certified CAM physician in CHF.

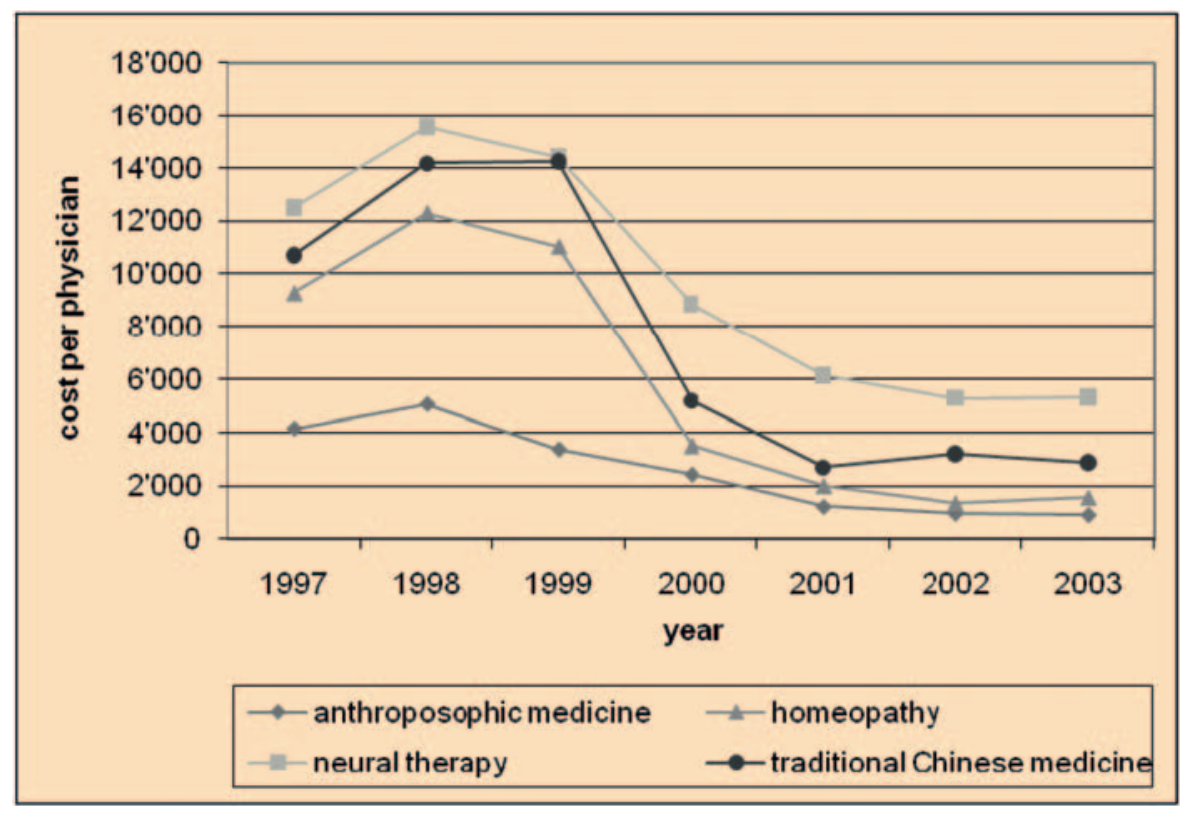

cine as for basic health insurance, i.e. $4.4 \%$ for the period from 1998 to 2002.

As a result, we obtained a decrease of costs for private health insurance for complementary medicine of CHF 34,300 per physician and of CHF 22.8 million for the total of all 663 CAM physicians in the year 2000. This implies that almost two-thirds of the increase of costs for outpatient complementary medicine at the expense of basic health insurance can be explained by a shift of costs from private to basic health insurance.

Shift of Costs Regarding Different Complementary Disciplines With regard to different complementary disciplines, it can be shown that the shift of costs was much less distinct for anthroposophic medicine (figs. 3, 4), whereas consultation costs at the expense of basic health insurance for homeopathy and for TCM increased considerably during 1998-2002. On the other hand, costs at the expense of private health insurance decreased simultaneously. In neural therapy, however, the increase of basic health insurance costs was more distinct than the decrease of private health insurance costs.

For homeopathy and TCM, the different decrease of costs at the expense of private health insurance compared to the other 2 complementary disciplines was mainly related to the respective tariff positions that were implemented in basic health insurance in July 1999. For acupuncture and for homeopathy, there were no such tariff positions before July 1999. Therefore, reimbursements were either provided by private health insurance for complementary medicine or, if patients were not insured accordingly, by out-of-pocket payments.

In contrast, the possibility of reimbursing anthroposophic medicine and neural therapy at the expense of basic health insurance existed already before July 1999. The respective de- crease of costs at the expense of private health insurance may be either related to other complementary services that were brought to account or was due to insurers shifting costs from private to basic health insurance after the year 1999.

\section{Further Components of the Increase of Consultation Costs of Certified CAM Physicians}

According to data obtained from the Versicherungszentrum AG (Insurance Center) in Zurich, more than $70 \%$ of the population with basic health insurance is also additionally insured for complementary medicine. However, for most of these health plans there are yearly limits of reimbursements for CAM-related treatments.

In cases where patients were either not insured or had reached their annual limits, it is therefore possible that complementary medicine had to be paid out of pocket before inclusion in basic health insurance. For the 2 major health insurers, Helsana Versicherungen AG and CSS Versicherung AG, the proportions of insured persons with an additional coverage for complementary medicine were 69 and $72 \%$, respectively, in 2000 .

There are no data available that document the extent of out-of-pocket payments for complementary services provided by certified physicians. Therefore, it can only be stated that, in addition to the shift of costs from private to basic health insurance, there was also a shift from out-of-pocket payments to coverage by basic health insurance after 1999. The financial extent of this mechanism, however, remains unknown as the respective data are not available, except that it was part of the CHF 12 million that cannot be explained by the shift from private to basic health insurance.

Another part of the CHF 12 million can be explained by favorable basic health insurance tariffs for complementary 
Fig. 5. Development of consultation costs at the expense of basic health insurance in 19972003 in cantons with or without favorable tariffs for complementary medicine; average per certified CAM physician in CHF. Cantons with favorable tariffs for CAM: AG, BE, GE, GL, JU, LU, NE, NW, OW, SG, SH, SZ, SO, TI, TG, UR, VD, ZG, ZH. Cantons without favorable tariffs for CAM: AR, AI, BL, BS, FR, GR, VS.

Fig. 6. Development of the number of basic services (consultations and home visits) brought to account at the expense of basic health insurance in 1997-2003 in cantons with or without favorable tariffs for complementary medicine; median per certified CAM physician. Cantons with favorable tariffs for CAM: AG, BE, GE, GL, JU, LU, NE, NW, OW, SG, SH, SZ, SO, TI, TG, UR, VD, ZG, ZH. Cantons without favorable tariffs for CAM: AR, AI, BL, BS, FR, GR, VS
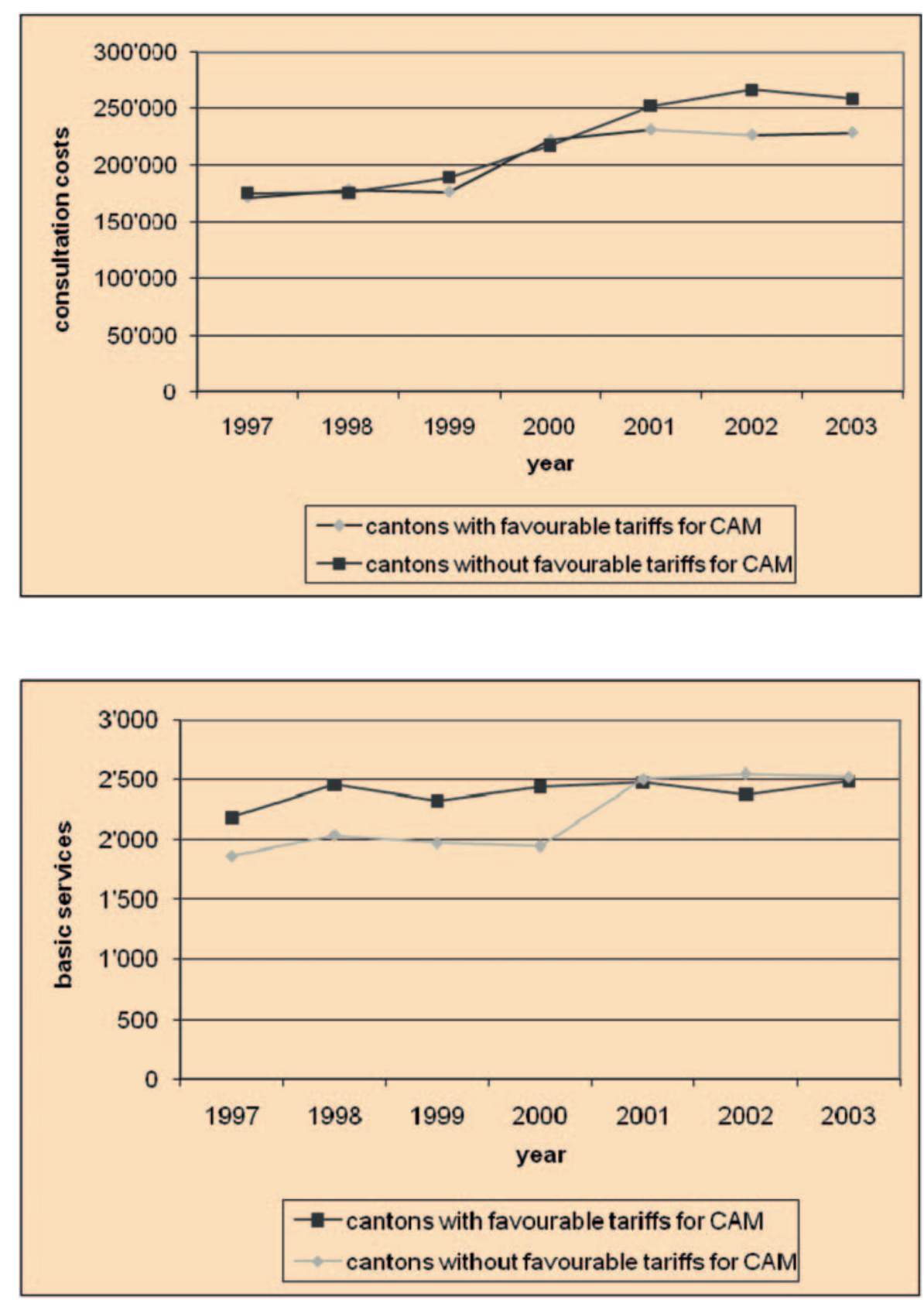

medicine. These tariff positions accounted for longer consultation times and other specific circumstances of complementary medicine and were higher than comparable tariffs for conventional medicine. Such tariffs were implemented in the majority of the Swiss cantons in the second half of 1999. In some cantons of Switzerland there were no such tariffs or they were so low that certified CAM physicians hardly made use of them. The development of average consultation costs in these 2 groups of cantons shows an increase in both, but to a different extent (fig. 5).

In cantons where favorable tariffs for complementary medicine had been implemented in the second half of 1999 , the main increase of costs took place between 1999 and 2000. On the other hand, in cantons without a favorable tariff for complementary medicine, the increase of costs was much more distinct, lasted for a longer period and was somewhat delayed. The most probable conclusion here is that certified CAM physicians tried to compensate the lack of higher tariffs for complementary medicine by an expansion of basic services.

Figure 6 shows this effect quite clearly. The median of the number of basic services (consultations and home visits) per physician reimbursed by basic health insurance increased considerably in cantons without favorable tariffs for complementary medicine between 2000 and 2001, whereas in cantons with a favorable tariff there was no increase of the number of services per physician after the year 1998.

As figure 7 shows, the increase of basic services in cantons without a favorable tariff for CAM was mainly related to an 
Fig. 7. Development of the yearly number of patients treated in 1997-2003 in cantons with or without favorable tariffs for complementary medicine; median per certified CAM physician. Cantons with favorable tariffs for CAM: AG, BE, GE, GL, JU, LU, NE, NW, OW, SG, SH, SZ, SO, TI, TG, UR, VD, ZG, ZH. Cantons without favorable tariffs for CAM: AR, AI, BL, BS, FR, GR, VS.

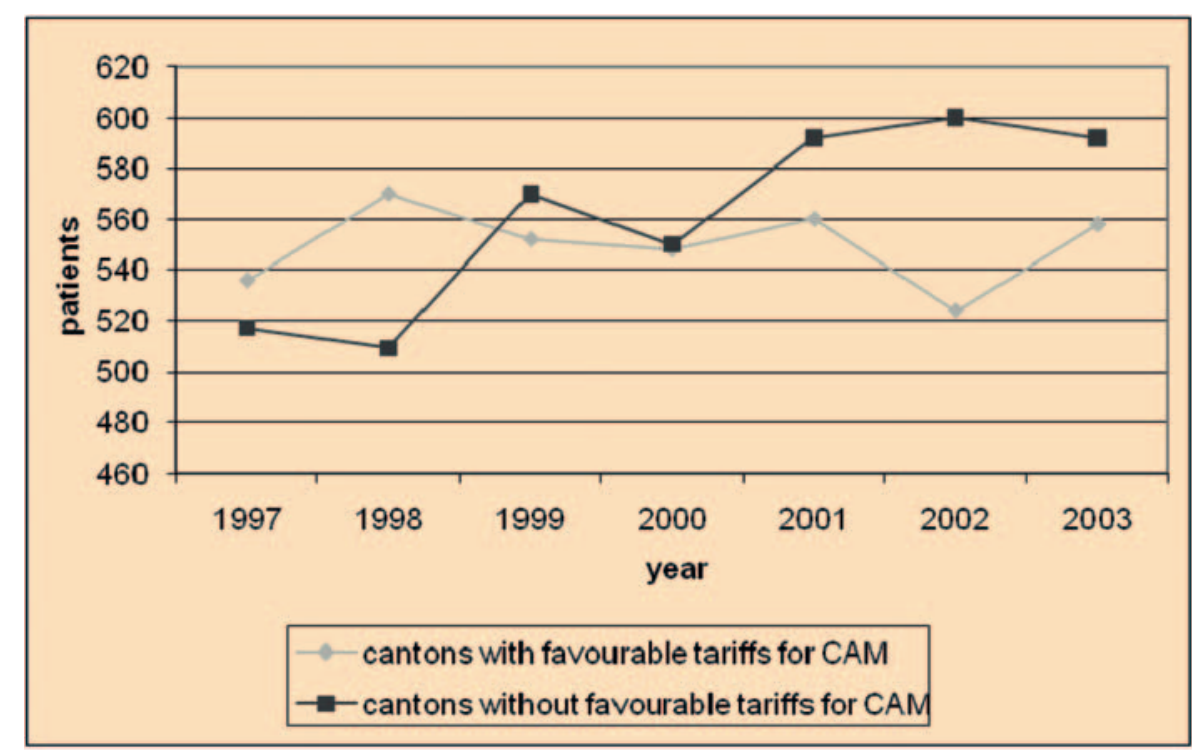

increase of patients treated per certified CAM physician, whereas the number of patients per physician slightly decreased in cantons with favorable tariffs for CAM after 1998. The yearly number of basic services per patient, however, hardly differed between the 2 groups of cantons.

\section{Discussion}

Our data show several major effects associated with the provisional inclusion of 5 complementary disciplines in basic health insurance in July 1999:

- There was a distinct increase in consultation costs at the expense of basic health insurance mainly between 1999 and 2000. However, this increase was much smaller than predicted by health authorities, scientists and health insurers.

- About two-thirds of the increase in consultation costs of CHF 35.9 million can be explained by the shift of costs from private to basic health insurance.

- Before 2004, each Swiss canton had its own tariff system, and there is no data available that would allow an analysis of the shift of expenses from private to basic health insurance; it was also not possible to calculate the monetary effect of favorable tariffs for CAM on the increase of consultation costs of certified CAM physicians during 1998-2002. Consequently, it was also not possible to evaluate the net increase of costs due to the increase in the average number of patients and in basic services per certified CAM physician in the 7 cantons without favorable tariff positions for CAM.

- However, both effects are also part of the CHF 12 million that cannot be explained by the shift of costs from private to basic health insurance. Furthermore, the direct cost effect of more patients treated was more distinct than the cost effect of favorable tariffs, but limited to fewer cantons.
- In cantons without favorable tariffs for CAM, certified CAM physicians probably tried to increase their income by providing more consultations, mainly by treating more patients. Whether this saved costs somewhere else in the health system because other physicians possibly treated fewer patients cannot be answered.

\section{Strengths and Limitations}

The survey was aimed at all CAM practitioners with 1 or multiple certificates for complementary medicine on the basis of the year 2000 (663 physicians). The proportion of responders in our sample of CAM physicians was sufficiently high (43.9\%) to allow conclusions with reference to the total of all 663 CAM practitioners in Switzerland in 2000, all the more because the geographical and gender distribution of the sample matched with that of the base population. The same is true for physicians without a certificate for CAM, even though their response rate was smaller.

Our study was designed to obtain cost estimates using primary and secondary base data sources. Therefore, the data has a number of limitations common to this type of research:

- The data pool of all Swiss health insurers (santésuisse) encompasses the majority of all expenditures covered by Swiss health insurers, but not all of the basic health insurers were able or willing to transmit their data electronically at that time. As a consequence, the data pool comprised only $94.8 \%$ of costs of all insured persons. We omitted an extrapolation of the data to $100 \%$ because it is uncertain whether cost data of the insurers that did not transmit their data to santésuisse correspond to those that did.

- With reference to private health insurance, our data were based on data from 2 major Swiss health insurers. Together these 2 companies insured $30.5 \%$ of all basic health insurants in 2000. In our study, basic and private health insurance costs at the expense of 2 health insurers were linked per physician. 
This allowed extrapolation of private health insurance costs for complementary medicine on the basis of total health insurance costs brought to account by the respective physician. Thereby we assumed that the overall proportion of patients with additional private insurance was equal to the patient population insured by the 2 insurers participating in the study.

- Cost data for TCM also encompasses acupuncture, which was definitely included in basic health insurance in 1996. It was not possible to discriminate between costs related to acupuncture and to other TCM procedures within our study. Therefore, the increase of CAM costs at the expense of basic health insurance also comprises substantial costs for acupuncture.

\section{External Validity}

To the best of our knowledge, cost effects of the inclusion of 5 complementary disciplines in Swiss basic health insurance were not systematically evaluated elsewhere, except that some of the results of this study were included in the final report of the program for the evaluation of complementary medicine (PEK) [11]. However, comparison of data of the Swiss health census of 1997 and 2002 showed that the proportion of the population that made use of these disciplines increased only slightly, at least for homeopathy and for herbal medicine (for homeopathy from $5.5 \%$ in 1997 to $6.1 \%$ in 2002) and that the increase was the same for procedures applied by physicians and by therapists whose services are not covered by basic health insurance [12]. This also indicates that the inclusion of 5 complementary disciplines in the Swiss basic health insurance did not result in a major supply-induced increase of costs [8].

On the contrary, since certified CAM physicians spend considerably longer on consultations and therefore treat fewer patients, it can be assumed that, in a health care system with a high density of physicians, the overall basic health insurance costs could even be lowered. In this respect other PEK data showed that a certified CAM physician causes $29 \%$ less costs at the expense of basic health care than a COM physician. Costs per patient, however, are comparable to those of COM physicians. These data include statistical adjustment for a total of 9 variables [13].

The spectrum of illnesses treated by certified CAM, noncertified CAM and COM physicians and the severity of health problems are different. Concerning patients of certified CAM physicians, the severity of health problems is considered higher by both patients and by physicians compared to patients of COM physicians. However, COM physicians treat more life-threatening illnesses. Non-certified CAM physicians range in between. However, what is considerably higher for certified CAM physicians, compared to both non-certified CAM and COM physicians, is the proportion of chronically ill patients [13]. It therefore can be argued that, all in all, certified CAM physicians most certainly do not treat lower-cost patients compared to non-certified CAM or COM physicians.
Concerning the question whether their treatment is substitutive, alternative or takes place in addition to COM, it has to be assumed that it is in general a combination of all three. However, also on this subject, other PEK data indicated that complementary medicine applied by certified physicians can substitute COM treatment mainly where hospital costs are concerned $[12,13]$. The German Anthroposophic Medicine Outcomes Study (AMOS) showed the same result at least for anthroposophic medicine $[14,15]$.

Furthermore, it has to be stated that complementary medicine applied by certified CAM physicians seemed to be as effective as conventional treatment and showed less adverse side effects. Patient satisfaction with treatment and physicians, on the other hand, was significantly higher with respect to certified CAM $[11,13]$. In this context, empowerment of patients seems to be a characteristic attribute of CAM applied by certified CAM physicians $[9,13]$.

\section{Implications for Health Policy}

In the context of a political decision whether to include CAM in basic health coverage, the findings of our study implicate the following conclusions:

- A growing proportion of the Swiss population attaches importance to complementary treatment within the health system $[16,17]$. If at least the most important complementary disciplines are reimbursed by basic health insurance, this gives equitable access to care for patients who choose CAM treatments without having to pay an additional premium for private health insurance or to provide out-of-pocket payments. This is especially true for people with a low income who now often only have the choice of a conventional medical treatment. On the other hand, with a proportion of $0.25 \%$ of total basic health insurance costs, the costs of the inclusion of 5 complementary disciplines into basic health insurance remained comparatively small.

- In order for physicians to choose to be certified in CAM, complementary procedures have to be reimbursed adequately, i.e. with respect to additional training required to be and to stay certified. This was not the case in some cantons of Switzerland, with the effect of an expansion of the number of basic services and of patients treated by certified CAM physicians. Additional research is needed on the respective impacts of the tariff system Tarmed that was implemented Swiss-wide in 2004 concerning this matter.

\section{Conclusions}

The inclusion of 5 complementary disciplines in basic health insurance only caused a minor increase of basic health insurance costs, which was much lower than predicted. According to the results of this study, the inclusion of CAM into Swiss basic health insurance would, if at all, represent only a small economic burden to Switzerland. 


\section{Acknowledgements}

We thank santésuisse, Helsana and CSS, the Swiss Medical Association as well as complementary medical associations for their data and support. Furthermore, we are indebted to all physicians who participated in the project.

\section{Disclosure Statement}

The study was funded by the Swiss Federal Office of Public Health in the context of a program to evaluate 5 complementary procedures provisionally included in Swiss basic health insurance (PEK). By contract, researches were independent from the funder. The authors declare that they have no competing interests.

\section{References}

1 Walach H, Linde K, Eichenberger R, Stalder H Kristensen FB, Kleijnen J: Summary consensus statement of the PEK review board regarding the PEK process and the PEK products. J Altern Complement Med 2006;12:347-348.

2 Geschäftsprüfungskommissionen und Geschäftsprüfungsdelegation der eidgenössischen Räte: Jahresbericht 2008. Bern, eidgenössische Räte, 23. Januar 2009, S 25.

3 Foppa D, Mäder Ph: Alternativmedizin: Couchepin räumt Fehler ein. Tages-Anzeiger, 30. Januar 2009.

4 Verbindung der Schweizer Ärztinnen und Ärzte (FMH): Ärztestatistik 1999-2003, Ärzte mit Praxistätigkeit, FMH-Schwerpunkte und FMH-Fähigkeitsausweise. $w w w . f m h . c h / f i l e s / p d f 4 / s 1999 . p d f, w w w$. fmh.ch/files/pdf4/sts2000-09.pdf, www.fmh.ch/files/ pdf4/sts2001-09.pdf, www.fmh.ch/files/pdf4/sts2002_ 09.pdf, www. fmh.ch/files/pdf4/sts2003-09.pdf.

5 Studer HP, Busato A: Basic health insurance expenditures for complementary and alternative medicine in primary care in Switzerland in 2002. Forsch Komplementärmed, submitted for publication.

6 Sommer JH, Bürgi M, Theiss R: Komplementärmedizin in der Krankenversicherung, Gesundheitsökonomische Analyse der Wirkungen des Einbezugs komplementärmedizinischer Leistungen in die Krankenversicherung. Basel, EMH Schweizerischer Ärzteverlag, 1998.
7 Kienle GS, Kiene H: Können aus der Studie 'Komplementärmedizin in der Krankenversicherung' wissenschaftlich tragfähige Schlüsse gezogen werden? Forsch Komplementärmed 1999;6:262-270.

8 BSV will Komplementärmedizin aktiv fördern. Medical Tribune, Nr. 49, 4. Dezember 1998

9 Busato A, Eichenberger R, Künzi B: Extent and structure of health insurance expenditures for complementary and alternative medicine in Swiss primary care. BMC Health Serv Res 2006;6:132.

10 Bundesamt für Gesundheit (Hrsg): Statistik der obligatorischen Krankenversicherung 2002. Bern, Bundesamt für Gesundheit, 2004.

11 Melchart D, Mitscherlich F, Amiet M, Eichenberger R, Koch P: Programm Evaluation Komplementärmedizin, Schlussbericht. Bern, Bundesamt für Gesundheit, 2005.

12 Crivelli L, Ferrari D, Limoni C: Inanspruchnahme von 5 Therapien der Komplementärmedizin in der Schweiz. Statistische Auswertung auf der Basis der Daten der Schweizerischen Gesundheitsbefragung 1997 und 2002. Manno, Scuola Universitaria Professionale della Svizzera italiana, Dipartimento scienze aziendali e sociali, 2004.
13 Studer HP, Busato A: Ist ärztliche Komplementärmedizin wirtschaftlich?; in Schweizerische Ärztezeitung, 2010;91:707-711; for an additional extended version: $w w w . s a e z . c h / p d f \_d / 2010 / 2010-18 / 2010-18$ 264.PDF.

14 Hamre HJ, Witt CM, Glockmann A, Ziegler R, Willich SN, Kiene H: Health costs in anthroposophic therapy users: a two-year prospective cohort study. BMC Health Serv Res 2006;6:65.

15 Hamre HJ, Witt CM, Glockmann A, et al.: Health costs in patients treated for depression, in patients with depressive symptoms treated for another chronic disorder, and in non-depressed patients: a two-year prospective cohort study in anthroposophic outpatient settings. Eur J Health Econ 2010; 11:77-94.

16 Leuenberger P, Longchamp C: Was erwartet die Bevölkerung von der Medizin?; in Stauffacher W, Bircher J (Hrsg): Zukunft Medizin Schweiz. Basel, Verlag EMH, 2002.

17 Schweizerische Gesellschaft für Gesundheitspolitik (SGGP) (Hrsg): The Future Patient in Switzerland. Das Gesundheitssystem der Zukunft aus Sicht von Bürgerin und Bürger. Muri BE, Schweizerische Gesellschaft für Gesundheitspolitik, 2003. 